This item was submitted to Loughborough's Research Repository by the author.

Items in Figshare are protected by copyright, with all rights reserved, unless otherwise indicated.

\title{
Users' ethical perceptions of social media research: Conceptualisation and measurement
}

\section{PLEASE CITE THE PUBLISHED VERSION}

https://doi.org/10.1016/j.jbusres.2020.03.005

\section{PUBLISHER}

Elsevier

\section{VERSION}

AM (Accepted Manuscript)

\section{PUBLISHER STATEMENT}

This paper was accepted for publication in the journal Journal of Business Research and the definitive published version is available at https://doi.org/10.1016/j.jbusres.2020.03.005.

\section{LICENCE}

CC BY-NC-ND 4.0

\section{REPOSITORY RECORD}

Michaelidou, Nina, Milena Micevski, and John Cadogan. 2020. "Users' Ethical Perceptions of Social Media Research: Conceptualisation and Measurement”. Loughborough University. https://hdl.handle.net/2134/11932866.v1. 
Users' Ethical Perceptions of Social Media Research: Conceptualisation and Measurement

Nina Michaelidou (corresponding author)

Department of Marketing and Retailing,

Loughborough University

Loughborough, Leicestershire UNITED KINGDOM

tel: +44 (0) 7919598004

e-mail: nina.michaelidou@ @ lboro.ac.uk

\section{Milena Micevski}

Department of International Marketing

Faculty of Business, Economics and Statistics

University of Vienna,

Oskar-Morgenstern-Platz 1, 1090, Vienna, Austria

tel: +43 (1) 427738040

e-mail: milena.micevski@univie.ac.at

John W. Cadogan

Professor of Marketing

Lougborough University

School of Business and Economics

Epinal Way, LE11 3TU, Loughborough, Leicestershire, UK

Phone: +44 (0)1509 222435

e-mail: j.w.cadogan@lboro.ac.uk 


\title{
Users' Ethical Perceptions of Social Media Research: Conceptualisation and Measurement
}

\begin{abstract}
The study examines users' ethical perceptions of social media research focusing on the conceptualisation and development of a measure. We follow an established procedure using a mixed-method research approach to develop and validate a measure involving two studies. Five ethical dimensions are identified in study one, anonymity and ownership, exploitation, permission, vulnerable groups, and control. The dimensionality of the measure is validated in study two, while construct validity is tested. Overall, the findings of both studies indicate that the developed measure possesses good psychometric properties; thus, fully capturing ethical dimensions of social media research and offering significant theoretical and practical contributions. This line of research has implications for varied stakeholders, including social media analysts and organisations engaging in social media research practices.
\end{abstract}

Keywords: Ethics; Social Media; Measure Development; Unobtrusive research; Social media research 


\section{Introduction}

In March 2018, news emerged that Cambridge Analytica was involved in the collection of identifiable personal data from more than 87 million Facebook users, in order to influence voter views on behalf of politicians. This instance of social media research (SMR) was "grossly unethical" (Liptak, 2018), with Facebook loosing $£ 40$ billion in market value in the space of a few hours of the scandal being announced (Kozlowska \& Karaian, 2018) and recently fined $\$ 5$ billion (The Guardian, 2019). In light of the scandal, three million European users abandoned Facebook, and stories of high-profile businesspeople and celebrities (e.g., Elon Musk, Steve Wozniak, Cher) removing themselves from the platform emerged. For many organisations, Facebook and similar social media platforms are critical for reaching and communicating with target markets, therefore the prospect of losing access in those markets because of unethical SMR by the social media platform, or third parties, is a very real concern. However, while potential social media user backlash to the perceived unethical behaviour of Facebook and Cambridge Analytica may influence these organisations in different ways, the long term and cumulative impact of users' ethical perceptions of social media researchers' activities remains largely unclear (Le \& Liaw, 2017; Martin, 2015).

Indeed, with every publicised data breach and each new ethical scandal on social media platforms, it seems likely that user awareness of ethical problems will increase, and that greater focus will be placed on the ethical standards employed by those engaging in SMR and social media researchers themselves. However, one problem with current scholarly research on social media is that the research community has yet to identify the key bases upon which social media users and other stakeholders judge the ethics of the research undertaken on these platforms (Le \& Liaw, 2017; Michaelidou \& Micevski, 2019). Yet, until scholars have pinpointed the main ways in which users ethically evaluate the activities of 
social media researchers, the advances cannot be made in terms of understanding the downsides of unethical SMR or the potential benefits of being perceived as a strong ethical player by users/individuals.

Past research within related domains indicates that individuals' ethical evaluations of SMR may be complex, and multi-faceted (Ashworth \& Free, 2006). We refer to SMR as involving the collection, storage and analysis of largely unremarkable social media data for various purposes by various stakeholders (e.g. market researchers, analysists and organisations, social media platforms), without users' knowledge and full disclosure of the data being collected, analysed and stored and by whom (Heath, Brooks, Cleaver, \& Ireland, 2009). This practice raises varied concerns which threaten the ethical well-being of social media users, primarily with regard to information privacy, sensitive populations and medical information $^{1}$ (e.g. online health and/or sexual communities), as well as control over one's personal information (Hine, 2011; O’Brien, 2010; Sveningsson, 2004). The relevance of this research is self-evident and topical, given the growing awareness of the ethical dilemmas many businesses are facing in their interfaces with social media platforms. Additionally, the importance of this study is made greater by the fact that ethical issues in research are generally underrepresented in business and management domains (Bell \& Bryman, 2007), with existing debates focusing on the issue of privacy/ethics in big data (e.g. Gleibs, 2014) and SMR practices, though without looking at the perspective of the users. This omission constitutes organisations and researchers that strive for the commercial value of big data, without the proper appreciation of the needs and perceptions of key stakeholders, such as the social media users, being seen as 'ignorant' (Nunan \& Di Domenico, 2013).

\footnotetext{
${ }^{1}$ GRINDR - a "dating app" have been allowing $3^{\text {rd }}$ parties to access user data, including users' HIV status (Singer, 2018).
} 
With the above assertions in mind, this study is the first to investigate facets of users' ethical perceptions of SMR. To this end, we offer several theoretical and practical contributions. First, and from a theoretical point of view, we study SMR from an 'ethical' perspective, and develop an empirical understanding of the facets of users' ethical perceptions of SMR. This contribution is substantial and novel as, to date, a measurement tool that captures users' ethical perceptions of SMR is non-existent. Additionally, we contribute to knowledge by extending current work which examines the ethicality of general business and management activities, as well as specific SMR and analytics practices (e.g. Brunk, 2010; Michaelidou \& Micevski, 2019). Second, in terms of practical utility, this study has implications for multiple stakeholders, including consumers who are social media users, market researchers and social media analysts, organisations, as well as the market research industry. Notably, understanding ethical perceptions of SMR assists in the development of an ethical climate surrounding the management and sustainability of SMR (e.g., providing insights to the development of ethical procedures in collecting 'live' social media data, as well as guidelines that take into consideration the interests of users as stakeholders). Moreover, such investigation will assist in building evidence-based strategies to cope with potential negative responses on social media, such as users' unwillingness to share information on social media platforms, or users abandoning social media in general. The following sections discuss the relevant literature with regard to online marketing research ethics, followed by a description of the methodology, the analysis and the discussion of the findings. The paper concludes with a discussion of the theoretical contributions of the study.

\section{Theoretical Background}

\subsection{Ethics and Research}


Ethics are a longstanding issue in business and management research, with previous scholarly work attempting to review ethical theories to explain individuals' moral judgments, and ethical behaviour (Barraquier, 2011; Bell \& Bryman, 2007; De Cremer et al., 2011; Treviño, Weaver \& Reynolds, 2006). For instance, Barraquier (2011) examines the determinants of ethical behaviour in organisations, stressing the experiential determinants grounded on moral philosophies and ethical standards, judgements and beliefs, that shape business practices. Similarly, Brunk (2010) focuses on perceived ethicality, which is argued to be a function of a number of different moral philosophies (Vitell, Singhapakdi \& Thomas, 2001), identifying spheres of corporate actions likely to elicit positive or negative ethical perceptions. Specifically, Brunk identifies six domains of organisational practices that are likely to trigger consumers' ethical perceptions. These aforementioned works, as well as those of other authors (e.g., Bartlett, 2003), refer to moral philosophy underpinning theories of ethics and guiding business practices, including deontological and consequentialist approaches. Deontological philosophies argue that acts are seen as inherently right or wrong, just or unjust, and that, as opposed to teleology or consequentialism, the end does not justify the means (Bartlett, 2003; Mingers \& Walsham, 2010). Adjunct to deontology is Kant's categorical imperative, which underlines the importance of actions to embed 'the concern for others'. Furthermore, this philosophy points out the importance of the duties and the expectations that individuals have in terms of being treated morally. Analogous to this, justice theory enacts the issue of fair treatment for moral reasons (Brebels, De Cremer, Van Dijke, \& Van Hiel, 2011), in the procedures an organisation adopts (Culnan \& Bies, 2003; Homans, 1961), positing that violations of fairness trigger ethical evaluations ${ }^{2}$ which are said

\footnotetext{
2 Ethical [as opposed to unethical] evaluations of actions and/or practices by individuals and organisations, are those that are perceived as fair and justifiable on the part of a larger community (Jones, 1991; Shalvi, Dana, Handgraaf, \& De Dreu, 2011).
} 
to lead to negative outcomes (Brunk, 2012; Culnan \& Bies, 2003).

Previous work (e.g., Bell \& Bryman, 2007) focuses specifically on management research practices, highlighting the importance of ethics. In particular, Bell and Bryman (2007) undertake a content analysis of ethics codes in social research, revealing a set of eleven ethical principles (e.g., privacy, informed consent, confidentiality, anonymity, reciprocity), the validity of which they challenge in terms of management research (Bell \& Bryman, 2007). They argue that management research reflects a context in which diversity and specific considerations should be addressed, yet focuses on ethical issues as integral components. Of particular interest to our study is Bell and Bryman's (2007) findings about 'covert' research, and the contention that it should be underpinned by ethical principles. More specifically, 'covert' or 'unobtrusive' research, while not so popular in offline environments, is a common practice on social media. This is due to organisations' efforts to extract and analyse information from social media in order to inform managerial decisions and to yield productivity and performance advantages (McAfee et al., 2012). Though SMR appears to be morally-unchallenged, given the lack of scholarly works on users' perceptions of SMR, it involves important ethical challenges for multiple stakeholders (Mingers \& Walsham, 2010), as everyone undertaking SMR may be compelled to engage in what some would call 'unethical behaviours' (De Cremer et al., 2011). For example, collecting information from social networking sites about employees, customers or other individuals without their knowledge and/or consent (Hine, 2011) given that this threatens users' privacy and exploits their personal data for commercial purposes (Castellacci \& Tveito, 2018). Indeed, it can be argued that unobtrusive research threatens the ethical validity of SMR, as issues of privacy and control are particularly salient within this context (O' Brien, 2010) due to ambiguities connected to what is considered 'private' or 'public' in an online context (e.g., Kornblum \& Marklein, 2006; Viégas, 2005). These contexts often overlap and, in most instances, are 
inseparable, thus making communication on social media available to the broader public (Cain \& Fink, 2010). While some scholarly attention has been paid to the aforementioned issues, we focus our attention on investigating domains which trigger ethical challenges in SMR.

\subsection{Online and Social Media Research Ethics}

The previous literature on online marketing research has focused on ethical and normative issues (Hammersley \& Traianou, 2011), with the focus being mainly directed on issues of privacy, control of information handling, public vs. private spaces, and informed consent (Buchanan \& Hvizdak, 2009; Moreno, Goniu, Moreno \& Diekema, 2013; Palmer, 2005; Weeden \& Williams, 2012). Additionally, researchers have focused on discussing common regulatory considerations or security risks associated with social media, as well as its implications for underage social media users (e.g. Boyd \& Crawford, 2012; Cain \& Flink, 2010; Light \& McGrath, 2010; Martin 2015; McKee, 2013; Moreno et al., 2013; Nunan \& Di Domenico, 2013). The following discussion provides an overview of the relevant ethics literature in this area.

Informational privacy refers to the "claim of individuals, groups, or institutions to determine for themselves when, how, and to what extent information about them is communicated to others" (Westin, 1967, p. 7). The concept has been extensively researched (e.g. Barnes, 2006; Brey, 2007; Hajli \& Lin, 2016; Martin, 2015; Roman, 2007; Roman \& Cuestas, 2008; Stead \& Gilbert, 2001; Tavani, 2000), as individuals are concerned about the loss of their personal information to organisations in online settings (Tavani, 2000). Relative to offline environments, expectations and awareness about informational privacy in digital spaces are particularly complex and conflicting in nature (Acquisti \& Gross, 2006; Boyd, 
2010; Hugl, 2011; Solove, 2007). For example, there is evidence to suggest that privacy on social media is considered highly important (Acquisti \& Gros, 2006; Hoadley, Xu, Lee \& Rosson, 2010) while, at the same time, users and particularly teen users, willingly share large amounts of personal information (Madden et al., 2013). Furthermore, privacy can be viewed from many perspectives (Barnes, 2006), with authors emphasizing the importance of the notions of the control and autonomy of users within the context of the Internet and social media, where agents are autonomous when it comes to controlling the sharing of their information (Gleibs, 2014; Hajli \& Lin, 2016; Marturano, 2011; Stalder, 2011). According to Foxman and Kilcoyne (1993) informational privacy reflects one's awareness about data collection practices (e.g. the processing of personal information, the observation of person's behaviours and his/hers interface with others) as well as the degree of control over one's information (also Gleibs, 2014; Schoeman, 1984). More specifically, awareness reflects the amount of information that an individual has about an organization's privacy practices (Foxman \& Kilcoyne, 1993). Awareness becomes salient in instances where an individual becomes (or intends to become) a user of an organisation's services, and this is manifested through the provision of users' agreements with an organization's privacy terms and conditions (Foxman \& Kilcoyne, 1993). Additionally, awareness is closely connected to an online media site, and whether or not users have read and agreed with the social media privacy terms and conditions. It is therefore not pertinent to covert research. On the contrary, control is manifested through approval, modification and the chance to opt-in or out (also Burgoon et al., 1989), and underpins unobtrusive research. In this case, there exists a complete absence of direct elicitation of data and the seeking of consent (Webb, Campbell, Schwartz \& Sechrest, 1966), whereby online users do not play an active role in data gathering, nor are they given prior information about the data collection activities of the organisations using the data, nor being given the opportunity to withdraw their information 
from such practices. Within the context of social media, control addresses the level that individuals feel that social media allows them to have oversight over the use of information via privacy settings (Hajli \& Lin, 2016). The authors argue that users need greater control of their personal information in order to ensure their privacy, while low levels of perceived control over information on social media platforms (e.g. Facebook) have been found to lead to negative outcomes on the part of consumers (Hoadley et al., 2010).

Furthermore, security is loosely related to the notion of privacy, and has been studied in relation to ethics (e.g. D'Arcy \& Hovav, 2009; Roman, 2007). The concept refers to the protection of individual data by securing confidentiality (such as security from allowing third party's to access, copy and disseminate personal information), and ensuring integrity and availability (Schoeman, 1992). Although security is an issue separate to privacy, the two concepts are frequently used interchangeably in the literature. This is because the core values of security (e.g. protection from potential adverse effects of others' behaviour) can be manifested or articulated via privacy (Schoeman, 1992). For example, the violation of data confidentiality might also breach a user's privacy rights. Within the context of social media, Hajli and Lin (2016) argue that the concept of security has been ethically challenged with regard to the usage of consumers' social media information for business purposes.

Concomitant to the above is the fact that online environments do not easily conform to the spatial configurations of public and private spaces, an aspect which is surrounded by ambiguity in the academic literature (Kornblum \& Marklein, 2006; Viégas, 2005).

Specifically, researchers argue that the boundaries between 'public and private' domains are drawn differently online relative to offline spaces (Koufaris, 2001; Waskul \& Douglas, 1996), and they are often unclear when it comes to social media users (Barnes, 2006; Katz \& Rice, 2002; Viégas, 2005). This includes underage users, who often willingly disclose private thoughts and behaviour which is then collected by marketers/organisations (Barnes, 
2006). Previous research confirms that in online spaces users may frequently describe their public posts as being private (Kozinets, 1998). Given the blurring of private vs. public that exists in online spaces when conducting online market research [and social media analytics thereafter] (Barnes, 2004; Bruckman, 2004), scholars argue that anonymity cannot be ensured due to the existence of tracking and other devices (Porr \& Ployhart, 2004). As such, these platforms provide social media analysts access to large amounts of unobtrusive personal information, online conversations (e.g. tweets) and behaviours that users think belong to them (Barnes, 2006; Gleibs, 2014; Markham, 2006). For example, Facebook users create profiles that provide information about themselves and their preferences and habits, which are then available to others given that they are posted on public spaces.

Last but not least, the protection of minors and other vulnerable groups (e.g. medical communities) in terms of their personal information being collected in online contexts, constitutes an ethical responsibility on the part of organisations and managers engaging in social media research (e.g., Hasnas, 1998; McKee, 2013). Social media are currently used as tools for disseminating public health information, with individuals frequently posting information about their medical conditions and seeking advice from others (De Choudhury, Gamon, Counts \& Horvitz, 2013). Similarly, adolescents are found to increasingly share information on social media compared with previously (Madden et al., 2013). Of particular concern is adolescents' usage of social media, given that it is increasing, with over $50 \%$ of 13-17 year olds visiting a social media site at least daily (AACAP, 2018) and over $80 \%$ of adolescents posting pictures of themselves, their interests and birthdates (Madden et al., 2013). This raises ethical concerns about how information posted by such groups is used by social media analysts, and whether the best interest of these groups is directly or indirectly taken into consideration in terms of such practices. The protection of these vulnerable groups in terms of their personal information being collected in online contexts, reflects an ethical 
dimension with regard to SMR, and highlights the responsibility of organisations and managers engaging in such practice (e.g. Hasnas, 1998; McKee, 2013).

\subsection{Users' Ethical Perceptions of SMR: Defining the Construct Domain}

In line with previous research in the area of business ethics (e.g. Roman, 2007) we define the domain of the construct of ethical perceptions of SMR as involving issues of privacy, security, control, consent, private and public spaces, and vulnerable groups. To further inform the definition of the domain of the construct, we conducted a review of the literature on the measurement of consumer ethical beliefs (e.g. Mitchell, Balabanis, Schlegelmilch \& Cornwell, 2009; Muncy \& Vitell, 1992; Roman, 2007; Roman \& Cuestas, 2008; Vitell \& Muncy, 2005). Consumers form perceptions about the ethicality of certain actions (Brunk 2010; Crane, 2001), and which reflect subjective judgments of right or wrong or good or bad (Brunk \& Bluemelhuber, 2011). Commonly, previous research has assessed the ethicality of specific behaviours or general business actions or practices, by assessing beliefs of righteousness or wrongness, thus capturing neutral or positively/negativelyvalenced sentiments (Bartels, 1967; Brunk, 2010; Muncy \& Vitell, 1992). Furthermore, to delineate the construct definition we also drew from existing research regarding the activities entailed in SMR including the collection, storage and subsequent analysis on unobtrusive social media data (Heath et al., 2009; Hajli \& Lin, 2016; Michaelidou \& Micevski, 2019). Based on the aforementioned, we define ethical perceptions of [unobtrusive] SMR in this study as reflecting: “individuals' subjective beliefs of the righteousness/wrongness of SMR activities (e.g. collection, storage and analysis) by various stakeholders and for various purposes, and which raise issues of privacy, control, security, consent and anonymity”. This definition allowed us to initially establish the confines of the construct, and to develop an 
initial understanding of its facets (Hinkin, 1995). This approach in defining of the theoretical construct is in line with existing arguments on scale development procedures which indicate that constructs reflect general abstractions (Kerlinger, 1986). In this case, the theoretical phenomenon of interest is 'users' ethical perceptions of SMR', without exemplifying specific purposes as to why the research is conducted and by whom, which interestingly, reflect specific instances of the concept of SMR (see Diamantopoulos, 2005). Given that individuals exhibit variation or asymmetry in terms of ethical perceptions as a result of possible tolerance (Brunk \& Bluemelhuber, 2011; Cohn, 2010; Lauby, 2012), our definition of the domain of the construct was put to test in the subsequent stage of the research to ensure measurement adequacy and content validity (Hinkin, 1995).

\section{Methods}

Following established measure development procedures (Churchill, 1979), we conducted a series of focus groups to better understand the domain of the construct. These enabled us to capture what actions consumers see as questionable or ethical/unethical as part of SMR, and to ensure the measurement adequacy and content validity of the construct (Hinkin, 1995). Data was collected via four focus groups with a purposive sample of twentyeight social media users. Participants included 36\% males and 64\% females, spread across the following age groups: $22 \%$ in the 18-24 age group, 54\% between the ages of 25 and 34 , $18 \%$ in the $34-44$ age group, and finally $7 \%$ in the $45-54$ and $55-65$ groups. Fifty percent of the respondents indicated that their education was at the undergraduate level and $32 \%$ at the PG level. Most participants were in employment, with $46 \%$ indicating an income of between $£ 16 \mathrm{~K}$ and $£ 25 \mathrm{~K}$ and $29 \%$ indicating an income above $£ 26 \mathrm{~K}$. Our sample closely reflects 
current social media usage trends (e.g. Statista, 2019a), thus ensuring the sample representativeness.

Each focus group discussion lasted approximately one hour. Throughout the discussion process, a semi-structured discussion guide was followed, based on the a priori themes identified in the literature. More specifically, the discussion guide included questions about social media usage (What social media do y use? How often do you use SM? Do you follow brands on SM? Do you engage with brands on SM? (consume/contribute content), awareness of unobtrusive social media research, issues (if any) connected to this type of research, what concerns they have in relation to this type of research, and whether there are any (other) ethical concerns arising from these issues. These questions were kept general on purpose so not to lead our respondents. After discussing these general concerns, we also asked some more specific questions if we saw that one focus group was more elaborate than another (e.g. Do you think companies may be collecting your social media data/posts etc. without your knowledge and consent? Do you think that companies should be collecting social media information, including personal information? What ethical issues, if any, might arise from this practice companies may be engaging?).

All the transcripts were subsequently analysed using QSR NVivo, where a thematic analytical process facilitated the identification and organisation of data resulting in codes and themes. Following this process, we were able to identify 23 items capturing five broad and salient themes (Crabtree \& Miller, 1999). While the themes identified were consistent with key issues discussed in the literature (i.e. privacy, control, vulnerable groups, and consent), respondents also exhibited concerns about their data being sold to others (i.e. exploitation). This theme complemented the existing a priori topics identified in the literature, and was therefore included in the subsequent analyses. Furthermore, in order to address the issue of item purification and assessment of content validity (Kimberlin \& Winterstein, 2008; Stone, 
1978), four academic experts in the area of business ethics evaluated the items after being introduced to the main purpose of the study. Based on the experts' assessment we: 1) collectively took the categorisations and provided an overall categorisation of items using the 5 dimensions, and 2) removed 5 items that indicated as 'overlapping' with others in the scale (Table 1).

Table 1 here.

\section{Analysis and Findings}

\subsection{Study 1}

Data Collection and Analysis. The first stage of data collection involved the use of questionnaires involving a sample of consumers in the UK. The aim was to assess the 18 items identified at the purification stage. All 18 items were measured on a 7-point Likert-type scale assessing 1- righteousness or 7 - wrongness of social media research activities. Potential issues with regard to common method bias were controlled via two approaches for minimizing such biases: 1) procedural and 2) statistical remedies (Podsakoff, MacKenzie, Lee \& Podsakoff, 2003). In terms of the procedural remedies, several approaches were used. First, the questionnaire included different format scale anchors for ethical beliefs statements, outcome variables (used subsequently for testing the predictive validity of the measure) and demographic questions, to minimise the potential for common method bias (Dillman, 2006). To further minimise any threats of response bias, we made sure that the respondents were informed about the purposes of the study and were asked to agree with the terms and conditions they were provided with in the introduction to the research. They were also 
informed that all the information obtained would remain anonymous and that no personal data would be recorded at any point (Podsakoff et al., 2003). Furthermore, respondents were unable to proceed with the questionnaire if they were either under-aged (under 18) or did not formally agree to take part in the survey. Only those participants using social media were allowed to proceed with the survey. In total, 202 fully completed questionnaires were obtained. Table 2 indicates the participants' demographic profile.

Table 2 here.

As a first step in the analysis, we examined the non-response bias. Having deemed it necessary to ensure the anonymity of our respondents and considering the relative sensitivity of the subject of the study, we were unable to identify the non-respondents and make inquiries about the reasons for their lack of response. Hence, we examined the non-response bias via the time trend extrapolation test where we compared the responses from the first and the last quartiles (Armstrong \& Overton, 1977). No significant differences were identified, suggesting that non-response bias is not an issue in our data.

Exploratory Factor Analysis (EFA). The 18 items were subsequently subjected to EFA using Principal axis factoring with an Oblimin rotation. The KMO (0.917) and Bartlett's test $\left(\chi^{2} / \mathrm{df}=3088.533 / 153 ; \mathrm{p} \leq 0.01\right)$ both indicate suitability for factor analysis. The EFA returned a clean 5 factor solution with no-cross loadings (Table 3). All factor loadings exceeded the 0.4 threshold (Hair et al., 2010), with a 5-factor solution explaining $73.251 \%$ of variance. Hence, the findings of the EFA indicated a five-dimensional structure with regard to the participants' ethical perceptions of SMR, with the factors identified as follows, 1) Anonymity and ownership; 2) Exploitation 3) Permission; 4) Vulnerable groups; 5) Control. 
Table 3 here.

The first factor - 'anonymity and ownership' - relates to the level of visibility of the personal data that users provide online. This issue is particularly salient on social media where once data has been posted on social media, it can easily be traced back to the user. Hence, what might feel that a private exchange or sharing of information is actually available to the wider public (Barnes, 2006; Eysenbach \& Till, 2001). Furthermore, 'exploitation' (factor 2) has been pointed out as an important issue in organisational research (e.g. Chen, Chiang \& Storey, 2012; Hempel \& Lehman, 2005; Zeng, Chen, Lusch \& Li, 2010). In the context of our research, the respondents believe that collecting and analysing individuals' data on social media that is subsequently used for marketing purposes is ethically questionable. This facet highlights the exploitation of personal information, reflecting on the information commoditization practices by market researchers and companies, including selling the information they collect to third parties (Barnes, 2004). The third factor, namely 'permission', tackles the issue of consented access to users' data, and is closely related to the issue of privacy. The respondents deemed it necessary for market researchers and social media analysts to clearly state the way (and ask for permission) in which data is collected, stored and transported (Garcia, Standlee, Bechkoff \& Cui, 2009; Sveningsson, 2004). Factor 4 ('vulnerable groups') addresses the ethicality of collecting data from minors and other vulnerable communities. Vulnerable users (e.g. medical patients) may not be utilizing the potential benefits offered by social media (e.g. an increase in social support, interconnectivity and awareness) (Idriss, Kvedar \& Watson, 2009) due to their perceptions about the lack of privacy and/or security on social media (e.g. dissemination of potentially erroneous, personal, health related information) (Eysenbach \& Till, 2001). Finally, the fifth factor - 'control' [over personal information] - is underpinned by informational privacy and security (Westin, 1967, 
p. 7). The literature on informational privacy construes control as instrumental to privacy protection, to the extent that certain definitions of privacy are actually reflected in one's control over one's personal information flow (e.g. Kang, 1998; Solove, 2007; Tavani \& Moor, 2001). In this case, control is manifested in terms of social media users' control of their personal information and content (e.g. posts, pictures, etc.) highlighting the need for direct consideration or representation of users' interests in social media analytic practices by organisations, by seeking to obtain direct permission.

Confirmatory Factor Analysis (CFA). A five-factor model emerging from EFA was specified in the CFA in which the items were allocated to the subsequent sub-scales that were identified in the previous stage. This stage was purely confirmatory, as the aim of this study was to check the stability of the five-dimensional solution identified. The initial CFA results returned a mediocre model fit, with a $\chi^{2}(125)=401.10, \mathrm{NNFI}=0.96, \mathrm{CFI}=0.967, \mathrm{SRMR}=$ 0.07 and RMSEA $=0.105$. Given the issue with the RMSEA value being higher than the recommended $\leq 0.08$ threshold (Bagozzi \& Yi, 2012) and considering that it is not uncommon in CFA model assessment for the implied model not to fit the observed data well on first estimation (Kelloway, 1998), we undertook further trimming of the scales. Accordingly, through an iterative process in which we identified items with highly correlated errors and low correlation among them, those items that performed poorly (5 items) were deleted from the model (Anderson \& Gerbing, 1988). Consequently, our final measurement model produced a good fit as all indicators performed within the recommended benchmark levels $\left(\chi^{2}(55)=111.02, \mathrm{NNFI}=0.977, \mathrm{CFI}=0.984, \mathrm{SRMR}=0.032\right.$ and $\left.\mathrm{RMSEA}=0.07\right)$ (Bagozzi \& Yi, 2012).

Reliability and Validity Assessment. To determine the scale reliability, coefficient alpha was calculated for each subscale identified through the CFA. Reliabilities exceeded the preferred level of 0.7 (Churchill, 1979) and ranged from 0.776 for "Exploitation" to 0.937 for 
"Observing vulnerable groups". These reliabilities are also above the Nunnally's (1978) suggested value of alpha of 0.5 or 0.6 at the early stages of research. To further evaluate the internal consistency of the scales, we computed composite reliability (CR) estimates and average variance (AVE) extracted estimates. The CR estimates ranged from 0.792 to 0.939 which are above the recommended threshold of 0.6 (Fornell \& Larcker, 1981) (Table 7). The results for the AVE estimates also exceeded the advocated level of 0.5 (Fornell \& Larcker, 1981). In addition, inter-items correlations indicate a strong internal consistency with regard to all the dimensions of the scale, with all the items belonging to their corresponding subdimension correlating strongly and meeting the minimum recommended threshold value of 0.35 (Hair et al., 2010). Finally, with regard to the nature of individual parameters and the model's internal structure, item loadings on their corresponding dimensions are all greater than the recommended 0.6 cut-off point (Bagozzi \& Yi, 1988). T-values for the loading are all highly significant $(\mathrm{p} \leq 0.01)$ and range from 6.49 to 12.13 . Taken collectively, Cronbach's Alpha estimates, composite reliability, average variance extracted, item-to-total correlations and item loadings all provided support for the reliability of the dimensions. Furthermore, we assessed convergent and discriminant validity; all AVE values exceed the recommended threshold of 0.5, and all AVE estimates for each of the constructs is greater than the squared correlation estimate for each pair of constructs (Fornell \& Larcker, 1981) (see Table 4). Hence, we conclude that the five factors meet the standard requirements for demonstrating discriminant validity.

Table 4 here.

Following the reliability and validity assessments, we undertook an additional step in validating the five-factor solution, and tested it against a four-factor solution. The choice of a 
four-factor solution was based on combining the two highest correlated factors, i.e. factor 3 (Permission) and factor 5 (Control). By comparing the fit indices, it is obvious that the fivefactor solution fits the data significantly better $\left(\chi^{2}(59)=245.048, \mathrm{NNFI}=0.94, \mathrm{CFI}=0.956\right.$, $\operatorname{SRMR}=0.04$ and RMSEA $\left.=0.125 ; \Delta \chi^{2}(\Delta \mathrm{df})=135.043(4)(\mathrm{p} \leq 0.01)\right)$. Consequently, these results demonstrate further the appropriateness of a five-factor solution.

Common Method Variance (CMV) Tests. Apart from using procedural remedies to tackle the potential issue of CMV (as describe earlier) we also employed statistical remedies (Podsakoff et al., 2003). To statistically test for CMV, we first performed the Harman's single-factor test (Podsakoff et al., 2003), as one of the most widely used tools for assessing the potential issues associated with common method bias. No single factor was uncovered which indicated that CMV was not a threat, the CMV single factor model fit is poor $\left(\chi^{2}(65)=\right.$ 629.76, NNFI $=0.804, \mathrm{CFI}=0.837, \mathrm{SRMR}=0.113$ and $\mathrm{RMSEA}=0.208)$, and the improvement in the model fit on moving from the CMV single factor model to the five-factor model is significant $\left(\Delta \chi^{2}(\Delta d f)=519.71(10)(p \leq 0.01)\right)$. However, as this method is not without its limitations, we added rigour to our CMV assessment by adding the additional marker variable test (Lindell \& Whitney, 2001). We used the item "How often do you play sports?" as a marker variable which, from a conceptual point of view, was unrelated to the constructs analyzed in our model. We performed a partial correlation analysis among the items measuring our constructs, and assessed whether or not the significance of the zeroorder correlations changed when the marker variable was partialled out. The significance of the resulting coefficients did not change, suggesting that CMV was not a problem in the analysis. Together, these two tests lead to the conclusion that CMV does not pose a threat for Study 1 .

\subsection{Study 2}


In the second stage of the research, we aimed to test the validity of the measure. To achieve this objective, we collected data from a new sample, in this case a sample of UK students. Student samples represent homogenous convenient samples with the ability to provide required information on the covariances between the items in the item pool (e.g. Koschate-Fischer, Diamantopoulos \& Oldenkotte, 2012; Sternthal, Tybout \& Calder, 1994). Additionally, student samples are widely used in academic research (e.g. Riefler \& Diamantopoulos, 2009). With regard to this study, students reflect a segment constituted of active social media users, spending at least 6 hours per day on social media sites (e-Marketer, 2015). In total, 238 responses were received. In terms of demographics, $47.5 \%$ were male and $52.5 \%$ female; $85 \%$ of them being between the ages of 18 and 24 ; and $68 \%$ having used social media tools for at least 6 years.

Similar to Study 1, we tested for non-response bias via a time trend extrapolation test and no significant differences were identified, suggesting that non-response bias is not an issue in our data. Next, similar to Study 1, we assessed CMV via Harman's single factor test and marker variable test, both of which showed that CMV was not an issue, the CMV single factor model fit is poor $\left(\chi^{2}(65)=568.75 ; \mathrm{NNFI}=0.825 ; \mathrm{CFI}=0.854 ; \mathrm{SRMR}=0.165\right.$ and RMSEA $=0.181$, and the improvement in model fit on moving from the CMV single factor model to the five-factor model is significant $\left(\Delta \chi^{2}(\Delta \mathrm{df})=460.79(10)(\mathrm{p} \leq 0.01)\right)$. We again performed a partial correlation analysis among the items measuring our constructs and assessed whether or not the significance of the zero-order correlations changed when the marker variable was partialled out. The significance of the resulting coefficients did not change, suggesting that CMV was not a problem in the analysis of Study 2.

Furthermore, following the results of Study 1, thirteen items were kept for further examination with a pre-specified five-factor model, and were entered into a confirmatory 
factor analysis (CFA) using the maximum likelihood estimation procedure, covariance matrix as input data implemented in LISREL 8.71. The measurement model produced a very good fit as all indicators performed within the recommended benchmark levels $\left(\chi^{2}(55)=107.96\right.$, $\mathrm{NNFI}=0.981, \mathrm{CFI}=0.987, \mathrm{SRMR}=0.04$ and RMSEA $=0.06)($ Bagozzi $\& \mathrm{Yi}, 2012)$. To determine the scale reliability, coefficient alpha was again calculated for each subscale identified through the CFA. Reliabilities exceeded the preferred level of 0.7 (Churchill, 1979) and ranged from 0.8 for 'anonymity and ownership' to 0.914 for 'Control'. Further examination of the CR and AVE values also shows that they are all above the recommended thresholds (0.60 for CR and 0.50 for AVE) (Bagozzi \& Yi, 1988; Nunnally, 1978). Moreover, we tested for discriminant validity by comparing all AVE values with the square of the correlations between each pair of constructs (Fornell \& Larcker, 1981) and provided a proof for the discriminant validity between the constructs (all AVE values are greater than the square of the correlations between each pair of latent constructs; see Table 5, Study 2). Table 6 provides a full list of the items for the five dimensions of ethical perceptions of SMR for Studies 1 and 2, each item's respective factor loading, and the descriptive statistics, Cronbach's $\alpha$, CR and AVE values for each of the measures. We again tested for the difference in fit between the four- and five- factor solution, and the results re-confirm the superiority of a five-factor solution, $\left(\chi^{2}(59)=342.32 ; \mathrm{NNFI}=0.931 ; \mathrm{CFI}=0.948 ; \mathrm{SRMR}=\right.$ 0.063 and $\left.\operatorname{RMSEA}=0.142 ; \Delta \chi^{2}(\Delta \mathrm{df})=234.36(4)(\mathrm{p} \leq 0.01)\right)$.

Tables 5\&6 here.

\subsection{Nomological and Predictive Validity}

To ascertain the nomological aspect of construct validity, the five dimensions were correlated with 'ethical research standards' of social media researchers (SMRs) as well as 
general perceptions of the (un)ethicality of SMR (Cadogan, Lee, Tarkiainen \& Sundqvist, 2009; Peter, 1981). Ethical research standards of SMRs set the norms for ethical behaviour and inform the decisions on what is the right thing to do (or what is the right behaviour) and what is not (Hunt, Wood \& Chonko, 1989). As a result, the SMR ethical perceptions scale is expected to be positively related to the perceptions of the ethical research standards of SMRs, as well as the overall perceptions of the ethicality of SMR. As anticipated, all relationships were found to be positive and significant at $p \leq 0.05$ (Table 7). Furthermore, to determine the predictive validity, the SMR ethics facets were correlated with a set of conceptually-related variables. Previous research provides ample support for the impact of ethical beliefs on consumers' retaliatory intentions or actions, such as boycotting (Brunk, 2010; Cohn, 2010; Hoadley et al., 2010). Predictive validity was assessed via the refusal to share/provide personal information on social media platforms and the falsification of information on social media platforms (Table 8) (e.g. Malhotra, Kim \& Agarwal, 2004; Sayre \& Horne, 2000; Schoenbachler \& Gordon, 2002). Additionally, concern for personal information has been closely linked to users' control of their information in online settings (Awad \& Krishna, 2006) and data ownership (Hoffman, Novak \& Peralta, 1999). Consumers who perceive that collecting consumers' data on social media is unethical will likely exhibit higher levels of concern on how the collected data might be used by the researchers. Finally, the falsification of, and refusal to provide, information on social media reflect two common strategies users frequently use to protect their privacy (Lampe, Ellison \& Steinfield, 2008; Lenhart \& Madden, 2007). As can be seen from Table 8, all anticipated linkages were significant at $\mathrm{p} \leq 0.05$, providing strong support for the nomological and predictive validity of the measures.

Tables $7 \& 8$ here. 


\section{Discussion and Implications}

\subsection{Theoretical Implications}

Prior work on ethical perceptions with regard to SMR from the point of view of users does not exist. Our study is original, and shows that there are five facets of ethical perceptions of SMR: anonymity and ownership, exploitation, permission, vulnerable groups, and control. Our results expand previous work on the ethics underpinning management research (Bell and Bryman, 2007; Culnan et al., 2010), by first identifying ethical facets which corroborate previously identified ethical principles such as privacy and anonymity. Second, and more important, we bring to light key issues such as the commercial exploitation of data collected via SMR, which reflects a business reality in the private sector (Malomo \& Sena, 2017), and also the issue of collecting information from vulnerable groups. Additionally, we confirm that individuals do not perceive the ethics of SMR invariably. Instead, there is asymmetry in ethical perceptions of SMR; as we find that although all mean values of constructs are significantly above the scale mid-point, users perceive lack of permission, anonymity and control as more unethical than exploitation (mean values of 4.49 and 3.66 for Study 1 and Study 2 respectively) and data collection from vulnerable groups (mean values of 5.19 and 4.92 for Study 1 and Study 2 respectively). There are two explanations for this: first, individuals see indirect, less immediate harm in some management actions (e.g., "denial of injury", Strutton, Vitell \& Pelton, 1994), which in our study would be that collecting data from such groups on social media is perceived as being less unethical, and outside of our respondents' direct harm or interest. Second, individuals exhibit a level of tolerance towards SMR because they enjoy a range of benefits from social media usage (e.g., economic, communication, self-expression). Also, we find that social media users won't 
mind if their data is collected. Rather, it is their inability to be directly represented within this process as major stakeholders (e.g., to have control), that forms stronger ethical perceptions, and is seen as being most unethical. This notion is in line with business ethics theory (Freeman \& Phillips, 2002) which highlights the responsibility of organisations to acknowledge that social media users are major stakeholders in social media analytic practices, and to consider their interests. Additionally, the findings are in accordance with previous work on ethical beliefs, suggesting that different dimensions of ethical beliefs will have a differentiating level of acceptability (Vitell \& Muncy, 1992).

Another important finding of our study is that ethical perceptions with regard to SMR lead to specific actions, such as refusal to provide information on social media and the falsification of information. These actions are resonant with previous work in the domain of ethics that emphasise individual responses as a result of perceived unethicality of management or corporate practices (Brunk \& Bluemelhuber, 2011). We provide evidence in this study that such actions are equally relevant for SMR in that they are perceived as unethical by social media users.

\subsection{Managerial Considerations}

SMR represents a great opportunity for organisations to capitalize on improving their decision making. Given its covert nature, SMR is also a context in which unethical actions can easily happen. Understanding how individuals perceive SMR is important for the ethical management of SMR and its reputation as an organisational practice. Thus, collecting information on platforms such as Facebook without the knowledge and consent of users, with the view to inform business decisions/strategies, can lead to high profile corporate scandals with political dimensions, as evident by the Cambridge Analytica/ Facebook incident. 
In this study, we delineated ethical perceptions of SMR and provide support to previous normative approaches in the sphere of the ethics of management research. On the basis of our results we present a number of interesting managerial reflections in areas where future research discussion might be fruitful. For example, are there benefits to greater cooperation or partnership between the social media platform and organisations engaging in SMR (e.g., private or public organisations) in order to adopt standards to safeguard the long-term viability of social media as data-driven decision-informing tools? Issues like permission, consent, and exploitation of data need to be integral in the ethical usage of such platforms when it comes to decision making. We therefore suggest the need for research into the benefits of different format 'consent pages', and measures to consistently ensure the age eligibility of social media users. Different procedures for seeking permission for the use of personal data should be evaluated to assess the value of social media users being directly involved in SMR practices (e.g. reciprocity). For instance, how would users react to explicit warning messages on social media platforms that inform them that their data (e.g., posts, messages, pictures, etc.) may be collected and analyzed for business and marketing purposes? Currently, social media users agree to terms and conditions of usage on specific platforms. However, they have no control of their data and how it may be subsequently used. Would users react negatively (ethical perceptions/use behaviour) to warning messages, and would negative responses be short-lived?

Furthermore, other considerations stemming from our research may relate to alternative business models that enhance users' control of their information and alleviate transparency. For example, how would social media users respond to optional usage fees that would ensure part or total exclusion of their data from SMR? This ground-breaking reflection regarding social media usage fees has the potential to shape current agreements/partnerships that organisations (e.g., private/ public/market research firms) currently have with the social 
media platforms, as well as to improve the ethical perceptions of SMR as a managerial practice. Organisations may also reflect on other ways to improve users' ethical perceptions of SMR. For instance, would improving transparency with regard to SMR (e.g. disclosure of the reasons why the data is collected, procedures of data extraction, usage, storage, and management), change users' ethical perceptions of SMR? Finally, we suggest that organisations look into whether offering assurances to users about ethical principles of anonymity, confidentiality and security, might be a way to tackle SMR ethical perceptions.

\section{Conclusions, Limitations and Future research}

Collecting consumers' personal information via social media platforms has become a popular method for market researchers and social media analysts due to its relative simplicity and cost-effectiveness (Acquisti \& Gross, 2006). The very nature of social media as a social communication tool encourages users to provide and exchange personal and even sensitive information which may easily become the target of researchers (Boyd, 2010). Many studies have pointed out the privacy and legal aspects connected to these practices, yet the ethical side of such activity has remained largely underdeveloped. This research set out to investigate users' ethical perceptions of SMR. We employed a deductive scale development procedure using mixed methods (Hinkin, 1995) and conducted two quantitative studies to develop and validate a measure capturing the ethical perceptions of SMR. We uncovered five facets in the form of anonymity and ownership, exploitation [of personal information], permission, vulnerable groups, and control [over personal information] which significantly affect consumers' refusal to share information and the falsification of information on social media. The identification of the facets of SMR ethics has both theoretical and practical implications. However, as with any other study in the domain of measure development, further validation 
may be necessary. Although the development process involved several stages in order to ensure construct validity (e.g. in determining predictive validity we controlled for certain internal conditions of the users such as negative past experiences with social media researchers), there might be other internal (e.g. users' personal characteristics) and external conditions (e.g. culture) that might affect consumers' ethical perceptions of SMR. In addition, distinguishing further among the type of information collected (e.g. personal data, opinions, photos) and the type of social media users (e.g. the privacy fundamentalists, Westin, 1991) might affect the ethical acceptability thresholds. Finally, although many social media platforms (e.g. Facebook and Twitter) share a set of core features, there are differences in the degree of presence across social media platforms (e.g. Kaplan \& Haenlein, 2010). And while, for example, certain social media platforms are higher in self-disclosure levels than others (such as blogs), other sites might have higher levels of social presence (e.g. virtual social worlds) (Kaplan \& Haenlein, 2010). Discriminating between different social media sites might uncover differences in users' opinions as to what is ethically acceptable and what is not, in terms of collecting information on specific social media platforms.

Furthermore, in this study we focused on users of social media research as they represent $67 \%$ of the UK population (Statista, 2019b). However, investigating ethical perceptions of SMR among non-users might lead us closer to the underlying reasons of not being part of or detaching oneself from social media, and will enhance the practical utility of the scale. Indeed, it might be that non-users (or previous users) value certain dimensions of the scale more strongly than the other dimensions and differently to the evaluation of existing users. This would provide additional valuable information to practitioners on why users become non-users and why non-users never become users. As such we encourage scholars to validate this scale with a non-user social media sample. 
Finally, to ascertain the nomological and predictive validity of our newly developed scale we correlated the scale with six variables which the literature suggested were related to aspects of social media researchers' ethicality - e.g. ethical standards of social media researchers or the intention to falsify private information on social media - and were measured using single item measures. Although current literature argues that the use of single item measures encourages the development of theoretically sophisticated models and permits stronger statistical control of potential confounders (Hayduk \& Littvay, 2012), future research may consider capturing these concepts using multiple items. Similarly, two of our dimensions have been captured by using two items, namely, exploitation and vulnerable groups. Even though our replication study supports the reliability and the validity of the scale and shows no indication of scale applicability threats, future research is needed to further validate our scale and assess its stability over time and across cultures. This would help further establish the validity of this newly developed SMR ethical perceptions scale and potentially lead to its further refinement. It may well be that, in some instance, a measurement instrument, when applied to other populations and types of organisations, might actually tap into different constructs (Cowles \& Crosby, 1986). Hence and additional question that remains is whether this scale is also applicable for tapping into ethical perceptions of SMR from the perspective of companies or social media analysts. Future research can examine whether managers see these ethical dimensions as salient, or whether managers' ethical perceptions of SMR differ to those of the social media users.

\section{References}

AACAP (2018). Social media and teens. Available online from:

https://www.aacap.org/AACAP/Families_and_Youth/Facts_for_Families/FFF-

Guide/Social-Media-and-Teens-100.aspx. [Accessed 29 Jan, 2020]. 
Acquisti, A., \& Gross, R. (2006). Imagined communities, Awareness, information sharing, and privacy on the Facebook. In G. Danezis and P. Golle, eds., International workshop on privacy enhancing technologies, Springer Berlin Heidelberg, pp. 36-58.

Anderson, J. C., \& Gerbing, D. W. (1988). Structural equation modeling in practice, A review and recommended two-step approach. Psychological Bulletin, 103(3), 411-423.

Armstrong, J. S., \& Overton, T. S. 1977. Estimating nonresponse bias in mail surveys. Journal of Marketing Research, 14(3), 396-402.

Ashworth, L., \& Free, C. (2006). Marketing dataveillance and digital privacy, Using theories of justice to understand consumers' online privacy concerns. Journal of Business Ethics, 67(2), 107-123.

Awad, N. F., \& Krishnan, M. S. (2006). The personalization privacy paradox, an empirical evaluation of information transparency and the willingness to be profiled online for personalization. MIS Quarterly, 30(1), 13-28.

Bagozzi, R. P., \& Yi, Y. (1988). On the evaluation of structural equation models. Journal of the academy of marketing science, 16(1), 74-94.

Bagozzi, R. P., \& Yi, Y. (2012). Specification, evaluation, and interpretation of structural equation models. Journal of the academy of marketing science, 40(1), 8-34.

Barnes, S. B. (2004). Issues of attribution and identification in online social research. In M. D. Johns, S. S. Chen, and G. J. Hall, eds., Online Social Research, Methods, issues, \& ethics, New York, Peter Lang, pp. 203-222.

Barnes, S. B. (2006). A privacy paradox, Social networking in the United States. First Monday, 11(9).

Barraquier, A. (2011). Ethical behaviour in practice: Decision outcomes and strategic implications. British Journal of Management, 22, S28-S46.

Bartels, R. (1967). A model for ethics in marketing. The Journal of Marketing, 31(1), 20-26. 
Bartlett, D. (2003). Management and business ethics: a critique and integration of ethical decision - making models. British Journal of Management, 14(3), 223-235.

Bell, E., \& Bryman, A. (2007). The ethics of management research: an exploratory content analysis. British journal of management, 18(1), 63-77.

Brebels, L., De Cremer, D., Van Dijke, M., \& Van Hiel, A. (2011). Fairness as social responsibility: A moral self - regulation account of procedural justice enactment. British Journal of Management, 22, S47-S58.

Brunk, K. H. (2012). Un/ethical company and brand perceptions: Conceptualising and operationalising consumer meanings. Journal of business ethics, 111(4), 551-565.

Boyd, D. (2010). Privacy and publicity in the context of big data. In Keynote Talk of the 19th Int'l Conf. on World Wide Web. Raleigh, North Carolina, USA.

Boyd, D., \& Crawford, K. (2012). Critical questions for big data, Provocations for a cultural, technological, and scholarly phenomenon. Information, communication \& society, 15(5), $662-679$.

Brey, P. (2007). Ethical aspects of information security and privacy. In M. Petković and W. Jonker, eds., Security, Privacy, and Trust in Modern Data Management, Springer Berlin Heidelberg, pp. 21-36.

Bruckman, A. (2004). Co-evolution of technological design and pedagogy in an online learning community. In S.A. Barab, R. Kling, and J.H. Gray, eds., Designing for Virtual Communities in the Service of Learning. Cambridge, Cambridge University Press.

Brunk, K. H. (2010). Exploring origins of ethical company/brand perceptions-A consumer perspective of corporate ethics. Journal of Business Research, 63(3), 255-262.

Brunk, K. H., \& Bluemelhuber, C. (2011). One strike and you're out, Qualitative insights into the formation of consumers' ethical company or brand perceptions. Journal of Business Research, 64(2), 134-141. 
Buchanan, E. A., \& Hvizdak, E. E. (2009). Online survey tools, Ethical and methodological concerns of human research ethics committees. Journal of Empirical Research on Human Research Ethics, 4(2), 37-48.

Burgoon, J. K., Parrott, R., Le Poire, B. A., Kelley, D. L., Walther, J. B., \& Perry, D. (1989). Maintaining and restoring privacy through communication in different types of relationships. Journal of Social and Personal Relationships, 6(2), 131-158.

Cadogan, J. W., Lee, N., Tarkiainen, A., \& Sundqvist, S. (2009). Sales manager and sales team determinants of salesperson ethical behaviour. European Journal of Marketing, 43(7-8), 907-937.

Cain, J., \& L. Fink, J. (2010). Legal and ethical issues regarding social media and pharmacy education. American journal of pharmaceutical education, 74(10), 184.

Castellacci, F., \& Tveito, V. (2018). Internet use and well-being: A survey and a theoretical framework. Research Policy, 47(1), 308-325.

Chen, H., Chiang, R. H., \& Storey, V. C. (2012). Business intelligence and analytics, From Big Data to Big Impact. MIS Quarterly, 36(4), 1165-1188.

Churchill Jr, G. A. (1979). A paradigm for developing better measures of marketing constructs. Journal of Marketing Research, 11, 64-73.

Cohn, D. Y. (2010). Commentary essay on 'exploring origins of ethical company/brand perceptions-A consumer perspective of corporate ethics'. Journal of Business Research, 63(12), 1267-1268.

Cowles, D., \& Crosby, L. A. (1986). Measure validation in consumer research: A confirmatory factor analysis of the voluntary simplicity lifestyle scale. Advances in Consumer Research, 13(1), 392-397.

Crabtree, B. F., \& Miller, W. L. (1999). Doing qualitative research. Sage publications.

Crane, A. (2001). Unpacking the ethical product. Journal of Business Ethics, 30(4), 361-373. 
Culnan, M. J., \& Bies, R. J. (2003). Consumer privacy, Balancing economic and justice considerations. Journal of social issues, 59(2), 323-342.

D’Arcy, J., \& Hovav, A. (2009). Does one size fit all? Examining the differential effects of IS security countermeasures. Journal of business ethics, 89(1), 59.

De Choudhury, M., Gamon, M., Counts, S., \& Horvitz, E. (2013). Predicting depression via social media. In Proceedings of the Seventh International AAAI Conference on Weblogs and Social Media, 2. Cambridge, Massachusetts, USA.

De Cremer, D., Van Dick, R., Tenbrunsel, A., Pillutla, M., \& Murnighan, J. K. (2011). Understanding ethical behavior and decision making in management: A behavioural business ethics approach. British Journal of Management, 22, S1-S4.

Diamantopoulos, A. (2005). The C-OAR-SE procedure for scale development in marketing: a comment. International Journal of Research in Marketing, 22(1), 1-9.

Dillman, D. A. (2006). Mail and internet surveys, The tailored design method (Vol. 2). New York, Wiley.

E-Marketer (2015). College students still spend most social time with Facebook. Available online from: https://www.emarketer.com/Article/College-Students-Still-Spend-Most-

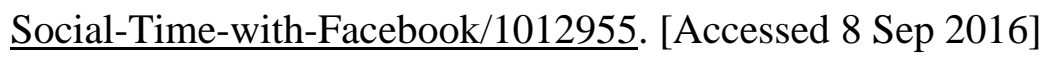

Eysenbach, G., and Till, J. E. (2001). Ethical issues in qualitative research on internet communities. British Medical Journal, 323(7321), 1103-1105.

Fornell, C., \& Larcker, D. F. (1981). Structural equation models with unobservable variables and measurement error, Algebra and statistics. Journal of Marketing Research, 18(3), 382-388.

Foxman, E. R., \& Kilcoyne, P. (1993). Information technology, marketing practice, and consumer privacy, Ethical issues. Journal of Public Policy \& Marketing, 12(1), 106-119. 
Freeman, R. E., \& Phillips, R. A. (2002). Stakeholder theory, A libertarian defence. Business Ethics Quarterly, 12(03), 331-349.

Garcia, A. C., Standlee, A. I., Bechkoff, J., \& Cui, Y. (2009). Ethnographic approaches to the internet and computer-mediated communication. Journal of Contemporary Ethnography, $38(1), 52-84$.

Gleibs, I. H. (2014). Turning virtual public spaces into laboratories, Thoughts on conducting online field studies using social network sites. Analyses of Social Issues and Public Policy, 14(1), 352-370.

Hajli, N., \& Lin, X. (2016). Exploring the security of information sharing on social networking sites, The role of perceived control of information. Journal of Business Ethics, 133(1), 111-123.

Hair, J. F., Black, W. C., Babin, B. J., Anderson, R. E., \& Tatham, R. L. (2010). Multivariate data analysis (Vol. 7). Upper Saddle River, NJ, Prentice Hall.

Hammersley, M., \& Traianou, A. (2011). Moralism and research ethics, a Machiavellian perspective. International Journal of Social Research Methodology, 14(5), 379-390.

Hasnas, J. (1998). The normative theories of business ethics, A guide for the perplexed. Business Ethics Quarterly, 8(01), 19-42.

Hayduk, L. A., \& Littvay, L. (2012). Should researchers use single indicators, best indicators, or multiple indicators in structural equation models? BMC medical research methodology, 12(1), 159.

Heath, S., Brooks, R., Cleaver, E., \& Ireland, E. (2009). Researching young people's lives. Sage.

Hempel, J., \& Lehman, P. (2005). The myspace generation. Business Week, 3963(88-93), 10.

Hine, C. 2011. Internet research and unobtrusive methods. Social Research Update, 61, 1. 
Hinkin, T. R. (1995). A review of scale development practices in the study of organisations. Journal of Management, 21(5), 967-988.

Hoadley, C. M., Xu, H., Lee, J. J., \& Rosson, M. B. (2010). Privacy as information access and illusory control, The case of the Facebook News Feed privacy outcry. Electronic Commerce Research and Applications, 9(1), 50-60.

Hoffman, D. L., Novak, T. P., \& Peralta, M. A. (1999). Information privacy in the marketspace, Implications for the commercial uses of anonymity on the Web. The Information Society, 15(2), 129-139.

Homans, G. C. (1961). Social behavior: Its elementary forms. Brace \& World, New York.

Hugl, U. (2011). Reviewing person's value of privacy of online social networking. Internet Research, 21(4), 384-407.

Hunt, S. D., Wood, V. R., \& Chonko, L. B. (1989). Corporate ethical values and organizational commitment in marketing. Journal of marketing, 53(3), 79-90.

Idriss S. Z., Kvedar, J. C., \& Watson, A. J. (2009). The role of online support communities, benefits of expanded social networks to patients with psoriasis. Archives of Dermatology, 145(1), 46-51.

Jones, T. M. (1991). Ethical decision making by individuals in organisations, An issuecontingent model. Academy of Management Review, 16(2), 366-395.

Kang, J. (1998). Information privacy in cyberspace transactions. Stanford Law Review, 50(4), 1193-1294.

Kaplan, A. M., \& Haenlein, M. (2010). Users of the world, unite! The challenges and opportunities of Social Media. Business Horizons, 53(1), 59-68.

Katz, J. E., \& Rice, R. E. (2002). Social consequences of Internet use, Access, involvement, and interaction. Cambridge, MA, MIT press. 
Kelloway, E. K. (1998). Using LISREL for structural equation modeling, A researcher's guide. London, Sage.

Kerlinger, FN (1986). Foundations of behavioral research. Fort Worth, TX: Holt, Rinehart and Winston.

Kimberlin, C. L., \& Winterstein, A. G. (2008). Validity and reliability of measurement instruments used in research. American journal of health-system pharmacy, 65(23), 2276-2284.

Kornblum, J., \& Marklein, M. B. (2006). What you say online could haunt you. USA Today, $9,1 \mathrm{~A}$.

Koschate-Fischer, N., Diamantopoulos, A., \& Oldenkotte, K. (2012). Are consumers really willing to pay more for a favorable country image? A study of country-of-origin effects on willingness to pay. Journal of International Marketing, 20(1), 19-41.

Koufaris, M. (2001). The search for a new identity, Post-organ transplant recipients and the Internet. In L. Chidambaram and Z. Ilze, eds., Our virtual world, The transformation of work, play and life via technology, London, Idea Group Publishing, pp. 291-33.

Kozlowska, H., and Karaian, J. 2018. The backlash against Facebook has destroyed $\$ 40$ billion in market value in a matter of hours, Available at: https://qz.com/1232563/cambridge-analytica-facebook-has-lost-40-billion-in-marketvalue-in-a-matter-of-hours/. Accessed: January $17^{\text {th }} 2020$.

Kozinets, R. V. (1998). On netnography, Initial reflections on consumer research investigations. Advances in Consumer Research, 25, 366-371.

Lampe, C., Ellison, N. B., \& Steinfield, C. (2008). Changes in use and perception of Facebook. In Proceedings of the 2008 ACM conference on Computer supported cooperative work, San Diego, CA, USA, pp. 721-730. 
Lauby, S. 2012. Ethics and Social Media, Where Should You Draw the Line? Available online from: https,//www.americanexpress.com/us/smallbusiness/openforum/articles/ethics-and-social-media-where-should-you-draw-the-line/. [Accessed 20 Oct 2016]

Le, T. M. \& Liaw (2017). Effects of pros and cons of applying big data analytics to consumers' responses in an E-commerce context. Sustainability. 9(5), 798.

Lenhart, A., \& Madden, M. (2007). Teens, privacy \& online social networks, How teens manage their online identities and personal information in the age of MySpace. Pew Internet \& American Life Project.

Light, B., \& McGrath, K. (2010). Ethics and social networking sites, A disclosive analysis of Facebook. Information Technology \& People, 23(4), 290-311.

Lindell, M. K., \& Whitney, D. J. (2001). Accounting for common method variance in crosssectional research designs. Journal of Applied Psychology, 86(1), 114.

Liptak, A. 2018. "Cambridge analytica's use of facebook data was a 'grossly unethical experiment'," Available at: https://www.theverge.com/2018/3/18/17134270/cambridgeanalyticas-facebook-data-underscores-critical-flaw-american-electorate. Accessed: January $17^{\text {th }} 2019$.

Madden, M., Lenhart, A., Cortesi, S., Gasser, U., Duggan, M., Smith, A., \& Beaton, M. (2013). Teens, social media, and privacy. Pew Research Center, 21, 1-107.

Magasi, S., Ryan, G., Revicki, D., Lenderking, W., Hays, R. D., Brod, M., ... \& Cella, D. (2012). Content validity of patient-reported outcome measures: perspectives from a PROMIS meeting. Quality of Life Research, 21(5), 739-746.

Malhotra, N. K., Kim, S. S., \& Agarwal, J. (2004). Internet users' information privacy concerns (IUIPC), The construct, the scale, and a causal model. Information Systems Research, 15(4), 336-355. 
Malomo, F., \& Sena, V. (2017). Data intelligence for local government? Assessing the benefits and barriers to use of big data in the public sector. Policy \& Internet, 9(1), 727.

Markham, A. N. (2006). Ethic as method, method as ethic, A case for reflexivity in qualitative ICT research. Journal of Information Ethics, 37, 1-20.

Martin, K. E. (2015). Understanding privacy online, Development of a social contract approach to privacy. Journal of Business Ethics, 137(3), 551-569.

Marturano, A. (2011). The Ethics of Online Social Networks-An Introduction. International Review of Information Ethics, 16, 3-5.

McAfee, A., Brynjolfsson, E., Davenport, T. H., Patil, D., \& Barton, D. (2012). Big data. The Management Revolution. Harvard Business Review, 90(10), 61-67.

McKee, R. (2013). Ethical issues in using social media for health and health care research. Health Policy, 110(2), 298-301.

Michaelidou, N., \& Micevski, M. (2019). Consumers' ethical perceptions of social media analytics practices: Risks, benefits and potential outcomes. Journal of Business Research, 104, 576-586.

Mingers, J., \& Walsham, G. (2010). Toward ethical information systems: the contribution of discourse ethics. MIS Quarterly, 34(4), 833-854.

Mitchell, V. W., Balabanis, G., Schlegelmilch, B. B., \& Cornwell, T. B. (2009). Measuring unethical consumer behaviour across four countries. Journal of Business Ethics, 88(2), $395-412$.

Moreno, M. A., Goniu, N., Moreno, P. S., \& Diekema, D. (2013). Ethics of social media research, common concerns and practical considerations. Cyberpsychology, Behaviour, and Social Networking, 16(9), 708-713. 
Muncy, J. A., \& Vitell, S. J. (1992). Consumer ethics, An investigation of the ethical beliefs of the final consumer. Journal of Business Research, 24(4), 297-311.

Nunan, D., \& Di Domenico, M. (2013). Market research and the ethics of big data. International Journal of Market Research, 55(4), 2-13.

Nunnally, J. (1978). Psychometric theory. New York, McGraw-Hill.

O'Brien, M. (2010). Unobtrusive research methods-An interpretative essay. Available online from: http://www.michelleobrien.net/wpcontent/uploads/2011/10/Michelle_OBrien_Unobtrusive_Research_Methods.pdf. [Accessed 30 Oct 2016].

Palmer, D. E. (2005). Pop-Ups, Cookies, and Spam, Toward a Deeper Analysis of the Ethical Significance of Internet Marketing Practices. Journal of Business Ethics, 58, 271-280.

Peter, J. P. (1981). Construct validity, A review of basic issues and marketing practices. Journal of Marketing Research, 18(2), 133-145.

Podsakoff, P. M., MacKenzie, S. B., Lee, J. Y., \& Podsakoff, N. P. (2003). Common method biases in behavioural research, a critical review of the literature and recommended remedies. Journal of Applied Psychology, 88(5), 879.

Porr, W. B., \& Ployhart, R. E. (2004). Organizational research over the Internet, Ethical challenges and opportunities. In E. A. Buchanan, ed., Readings in Virtual Research Ethics. Issues and Controversies, Hershey, PA, Information Science Publishing, pp. $130-155$.

Riefler, P., \& Diamantopoulos, A. (2009). Consumer cosmopolitanism, Review and replication of the CYMYC scale. Journal of Business Research, 62(4), 407-419.

Roman, S. (2007). The ethics of online retailing, a scale development and validation from the consumers' perspective. Journal of Business Ethics, 72(2), 131-148. 
Roman, S., \& Cuestas, P. J. (2008). The perceptions of consumers regarding online retailers' ethics and their relationship with consumers' general internet expertise and word of mouth, a preliminary analysis. Journal of Business Ethics, 83(4), 641-656.

Sayre, S., \& Horne, D. 2000. Trading secrets for savings, how concerned are consumers about club cards as a privacy threat? In S. J. Hoch and R. J. Meyer, eds., NAAdvances in Consumer Research, Provo, UT, 151-155.

Schoeman, F. D. (1984). Philosophical dimensions of privacy, An anthology. Cambridge University Press.

Schoeman, F. D. (1992). Privacy and social freedom. Cambridge, Cambridge university press.

Schoenbachler, D. D., \& Gordon, G. L. (2002). Trust and customer willingness to provide information in database-driven relationship marketing. Journal of Interactive Marketing, $16(3), 2-16$.

Shalvi, S., Dana, J., Handgraaf, M. J., \& De Dreu, C. K. (2011). Justified ethicality: Observing desired counterfactuals modifies ethical perceptions and behavior. Organizational Behavior and Human Decision Processes, 115(2), 181-190.

Singer, N. (2018). Grindr Sets Off Privacy Firestorm After Sharing Users' H.I.V.-Status Data. Available online from: https://www.nytimes.com/2018/04/03/technology/grindr$\underline{\text { sets-off-privacy-firestorm-after-sharing-users-hiv-status-data.html. [Accessed } 17}$ November 2019]

Solove, D. J. (2007). The future of reputation, Gossip, rumor, and privacy on the Internet. Yale University Press.

Stalder, F. (2011). Autonomy beyond privacy? A rejoinder to Colin Bennett. Surveillance \& Society, 8(4), 508-512. 
Statista (2019a). Distribution of Facebook users worldwide as of October 2019, by age and gender. Available online from: https://www.statista.com/statistics/376128/facebookglobal-user-age-distribution/.[Accessed 7 January 2020]

Statista (2019b). Active social media penetration in selected European countries in January 2019. Available online from: https://www.statista.com/statistics/295660/active-socialmedia-penetration-in-european-countries/.[Accessed 10 January November 2020]

Stead, B. A., \& Gilbert, J. (2001). Ethical issues in electronic commerce. Journal of Business Ethics, 34(2), 75-85.

Sternthal, B., Tybout, A. M., \& Calder, B. J. (1994). Experimental design, Generalization and theoretical explanation. In B. Calder, ed., Principles of Marketing Research, Cambridge, MA, Blackwell, pp. 195-223.

Stone, E. (1978). Research methods in organizational behaviour. Glenview, IL, Scott, Foresman.

Strutton, D., Vitell, S. J., \& Pelton, L. E. (1994). How consumers may justify inappropriate behavior in market settings: An application on the techniques of neutralization. Journal of Business Research, 30(3), 253-260.

Sveningsson, M. (2004). Ethics in Internet ethnography. In E. A. Buchanan, ed., Readings in virtual research ethics, Issues and controversies, Hershey, PA, Information Science Publishing, pp. 45-61.

Tavani, H. (2000). Privacy and security. In D. Langford, ed., Internet Ethics, London, Macmillan, pp. 65-95.

Tavani, H. T., \& Moor, J. H. (2001). Privacy protection, control of information, and privacyenhancing technologies. In R. A. Spinello and H. T. Tavani, eds., Readings in Cybernetics, Sudbury, Massachusetts, Jones and Bartlett, pp. 378-391. 
The Guardian (2019). Facebook to be fined \$5bn for Cambridge analytica privacy violationsreports. Available online from:

https://www.theguardian.com/technology/2019/jul/24/facebook-to-pay-5bn-fine-asregulator-files-cambridge-analytica-complaint (accessed July 12, 2019).

Treviño, L. K., Weaver, G. R., \& Reynolds, S. J. (2006). Behavioral ethics in organizations: A review. Journal of management, 32(6), 951-990.

Viégas, F. B. (2005). Bloggers' expectations of privacy and accountability, An initial survey. Journal of Computer-Mediated Communication, 10(3), 1-31.

Vitell, S. J., \& Muncy, J. (2005). The Muncy-Vitell consumer ethics scale, A modification and application. Journal of Business Ethics, 62(3), 267-275.

Vitell, S. J., Singhapakdi, A., \& Thomas, J. (2001). Consumer ethics: an application and empirical testing of the Hunt - Vitell theory of ethics. Journal of Consumer Marketing, $18(2), 153-178$.

Waskul, D. \& Douglas, M. (1996). Considering the Electronic Participant, Some Polemical Observations on the Ethics of Online Research. The Information Society, 12,129-39.

Webb, E. J., Campbell, D. T., Schwartz, R. D., \& Sechrest, L. (1996). Unobtrusive Measures, nonreactive research in the social sciences. Chicago, Rand McNally.

Weeden, M. R., \& Williams, G. (2012). Ethics and on-line research methodology. Journal of Social Work Values and Ethics, 9(1), 40-51.

Westin, A. F. (1967). Privacy and freedom. New York, Atheneum.

Westin, A. F. (1991). Domestic and International Data Protection Issues; How the American Public Views Consumer Privacy Issues in the Early 90s and Why? Testimony before the Subcommittee on Government Information and Agriculture, Committee on Government Relations, U.S. House of Representatives, Washington, D.C, U.S. Government Printing Office, pp. 54-68. 
Zeng, D., Chen, H., Lusch, R., \& Li, S. H. (2010). Social media analytics and intelligence. IEEE Intelligent Systems, 25(6), 13-16. 
Table 1: Ethical Perceptions of Social Media Research Pool of Items following Purification Stage

1. Collecting information on social media (SM) users that users think is not visible to others

2. Collecting SM users' information that users think belongs to them

3. Failing to keep the collected information on SM anonymous

4. Using collected SM information for research purposes

5. Using collected SM information for marketing purposes

6. Collecting information on SM without permission

7. Storing information collected on social media without permission

8. Using tracking devices to observe SM activity without valid consent

9. Selling collected SM information to third parties

10. Disclosing SM information to third parties without consent

11. Keeping the SM information for longer than needed

12. Collecting data from underage users

13. Collecting data from vulnerable groups (e.g. medical, sexual)

14. Neglecting to safeguard the information collected from SM users

15. Failing to allow users to have control over their information once collected

16. Denying users the right to choose if they wish their data to be collected

17. Neglecting to inform users that they will be the object of market research on SM

18. Failing to allow users to opt-out 
Table 2: Study1 descriptive statistics

\begin{tabular}{|c|c|c|}
\hline Non-student sample & $\mathbf{n}$ & Percentage $\%$ \\
\hline \multicolumn{3}{|l|}{ Gender } \\
\hline Male & 76 & 37.6 \\
\hline Female & 126 & 62.4 \\
\hline \multicolumn{3}{|l|}{ Age } \\
\hline $18-24$ & 18 & 8.9 \\
\hline $25-34$ & 73 & 36.1 \\
\hline $35-54$ & 88 & 43.6 \\
\hline 55 and over & 23 & 11.4 \\
\hline \multicolumn{3}{|l|}{ Income } \\
\hline Less than $£ 10000$ & 13 & 6.4 \\
\hline$£ 10001$ to $£ 19999$ & 45 & 22.3 \\
\hline$£ 2000$ to $£ 29999$ & 57 & 28.2 \\
\hline$£ 30000$ to $£ 39999$ & 31 & 15.3 \\
\hline$£ 40000$ and more & 56 & 27.7 \\
\hline \multicolumn{3}{|l|}{ Social media usage } \\
\hline 1-less than 2 years & 4 & 2.0 \\
\hline 2-less than 3 years & 10 & 5.0 \\
\hline 3-less than 4 years & 18 & 8.9 \\
\hline 4-less than 5 years & 17 & 8.4 \\
\hline 5-less than 6 years & 28 & 13.9 \\
\hline 6-less than 7 years & 16 & 7.9 \\
\hline 7 years and longer & 109 & 54.0 \\
\hline \multicolumn{3}{|c|}{ Time spent on social media weekly } \\
\hline $1-30$ minutes & 2 & 1.0 \\
\hline $31-59$ minutes & 29 & 14.4 \\
\hline 1-2 hours & 24 & 11.9 \\
\hline 2.1-4 hours & 45 & 22.3 \\
\hline 4.1-8 hours & 54 & 26.7 \\
\hline More than 8 hours & 48 & 23.8 \\
\hline
\end{tabular}


Items:

1. Collecting information on social media (SM) users that users think is not visible to others

2. Collecting SM users' information that users think belongs to them

3. Failing to keep the collected information on SM anonymous\#

4. Using collected SM information for research purposes

5. Using collected SM information for marketing purposes

6. Collecting information on SM without permission

7. Storing information collected on social media without permission

8. Using tracking devices to observe SM activity without valid consent\#

9. Selling collected SM information to third parties\#

10. Disclosing SM information to third parties without consent

11. Keeping the SM information for longer than needed\#

12. Collecting data from underage users

13. Collecting data from vulnerable groups (e.g. medical, sexual)

14. Neglecting to safeguard the information collected from SM users\#

15. Failing to allow users to have control over their information once collected

16. Denying users the right to choose if they wish their data to be collected

\begin{tabular}{|c|c|c|c|c|}
\hline \multicolumn{5}{|c|}{ Factors in EFA* } \\
\hline 1 & 2 & 3 & 4 & 5 \\
\hline \multicolumn{5}{|c|}{-.847} \\
\hline \multirow{2}{*}{\multicolumn{5}{|c|}{$\begin{array}{l}-.745 \\
-.560\end{array}$}} \\
\hline & & & & \\
\hline & .836 & & & \\
\hline & .690 & & & \\
\hline & & -.568 & & \\
\hline & & -.692 & & \\
\hline & & -.821 & & \\
\hline & & -.597 & & \\
\hline & & -.789 & & \\
\hline & & -.419 & & \\
\hline & & & .966 & \\
\hline & & & .927 & \\
\hline & & & & .484 \\
\hline & & & & .623 \\
\hline & & & & .865 \\
\hline & & & & .848 \\
\hline & & & & .801 \\
\hline
\end{tabular}

17. Neglecting to inform users that they will be the object of market research on SM

18. Failing to allow users to opt out

Note: * Factors: 1- anonymity and ownership; 2 - exploitation; 3 - permission; 4 - vulnerable groups; 5- control \# items dropped at a later stage of analysis

Table 4: Correlations and Discriminant Validity of the Constructs (Study 1)

\begin{tabular}{lccccc}
\hline & 1 & 2 & 3 & 4 & 5 \\
\hline 1. Anonymity and Ownership & $\mathbf{0 . 8 1}$ & 0.30 & 0.40 & 0.16 & 0.43 \\
2. Exploitation & 0.55 & $\mathbf{0 . 6 6}$ & 0.27 & 0.14 & 0.20 \\
3. Permission & 0.63 & 0.52 & $\mathbf{0 . 7 9}$ & 0.16 & 0.70 \\
4. Vulnerable Groups & 0.40 & 0.38 & 0.40 & $\mathbf{0 . 8 9}$ & 0.15 \\
5. Control & 0.66 & 0.45 & 0.84 & 0.39 & $\mathbf{0 . 7 6}$ \\
\hline
\end{tabular}

Note: Correlations are below diagonal, squared correlations are above the diagonal, and AVE estimates are presented on the diagonal

Table 5: Correlations and Discriminant Validity of the Constructs (Study 2)

\begin{tabular}{lccccc}
\hline & 1 & 2 & 3 & 4 & 5 \\
\hline 1. Anonymity and Ownership & $\mathbf{0 . 6 7}$ & 0.14 & 0.40 & 0.13 & 0.39 \\
2. Exploitation & 0.37 & $\mathbf{0 . 7 5}$ & 0.12 & 0.12 & 0.11 \\
3. Permission & 0.63 & 0.35 & $\mathbf{0 . 7 3}$ & 0.20 & 0.71 \\
4. Vulnerable Groups & 0.36 & 0.35 & 0.45 & $\mathbf{0 . 8 2}$ & 0.30 \\
5. Control & 0.62 & 0.33 & 0.84 & 0.55 & $\mathbf{0 . 7 3}$ \\
\hline
\end{tabular}

Note, Correlations are below diagonal, squared correlations are above the diagonal, and AVE estimates are presented on the diagonal 
Table 6: Constructs used in the study and factor loadings, 1(low)-7 (high)

\begin{tabular}{|c|c|c|c|c|c|c|c|c|c|c|}
\hline \multirow{2}{*}{$\begin{array}{c}\text { Scale } \\
\text { Items: }\end{array}$} & \multicolumn{2}{|c|}{$\begin{array}{l}\text { Anonymity and } \\
\text { ownership }\end{array}$} & \multicolumn{2}{|c|}{ Exploitation } & \multicolumn{2}{|c|}{ Permission } & \multicolumn{2}{|c|}{ Vulnerable groups } & \multicolumn{2}{|c|}{ Control } \\
\hline & St.1 & St. 2 & St.1 & St.2 & St.1 & St.2 & St.1 & St.2 & St.1 & St. 2 \\
\hline $\begin{array}{l}\text { Collecting information on social media (SM) users that users think } \\
\text { is not visible to others }\end{array}$ & 0.889 & 0.817 & & & & & & & & \\
\hline Collecting SM users' information that users think belongs to them & 0.905 & 0.817 & & & & & & & & \\
\hline Using collected SM information for research purposes & & & 0.691 & 0.864 & & & & & & \\
\hline Using collected SM information for marketing purposes & & & 0.918 & 0.864 & & & & & & \\
\hline Collecting information on social media without permission & & & & & 0.925 & 0.873 & & & & \\
\hline Storing information collected on social media without permission & & & & & 0.921 & 0.889 & & & & \\
\hline Disclosing of SM information to third parties without consent & & & & & 0.817 & 0.792 & & & & \\
\hline Collecting data from underage users & & & & & & & 0.895 & 0.906 & & \\
\hline Collecting data from vulnerable groups (e.g. medical, sexual) & & & & & & & 0.985 & 0.906 & & \\
\hline $\begin{array}{l}\text { Failing to allow users to have control over their information once } \\
\text { collected }\end{array}$ & & & & & & & & & 0.773 & 0.829 \\
\hline $\begin{array}{l}\text { Denying users the right to choose if they wish their data to be } \\
\text { collected }\end{array}$ & & & & & & & & & 0.901 & 0.885 \\
\hline $\begin{array}{l}\text { Neglecting to inform users that they will be the object of market } \\
\text { research on SM }\end{array}$ & & & & & & & & & 0.920 & 0.884 \\
\hline Failing to allow users to opt-out & & & & & & & & & 0.888 & 0.812 \\
\hline Mean & 5.93 & 5.4 & 4.49 & 3.66 & 6.26 & 5.8 & 5.19 & 4.92 & 6.16 & 5.67 \\
\hline Standard Deviation & 1.42 & 1.37 & 1.64 & 1.47 & 1.32 & 1.48 & 1.84 & 1.73 & 1.27 & 1.32 \\
\hline Cronbach's $\alpha$ & 0.891 & 0.8 & 0.776 & 0.854 & 0.912 & 0.887 & 0.937 & 0.902 & 0.925 & 0.914 \\
\hline Composite Reliability & 0.892 & 0.801 & 0.792 & 0.855 & 0.919 & 0.888 & 0.939 & 0.902 & 0.927 & 0.914 \\
\hline Average Variance Extracted & 0.81 & 0.67 & 0.66 & 0.75 & 0.79 & 0.73 & 0.89 & 0.82 & 0.76 & 0.73 \\
\hline Model fit statistics, & $\chi^{2}$ & d & & $\mathrm{X}^{2} / \mathrm{df}$ & & & CFI & SRI & & ISEA \\
\hline Study 1 & 111.02 & 55 & & 2.00 & & & 0.984 & 0.0 & & .07 \\
\hline Study 2 & 107.96 & 55 & & 1.96 & & & 0.987 & 0.0 & & .06 \\
\hline
\end{tabular}

Note: St. 1 - Study 1; St. 2 - Study 2 
Table 7: Nomological Validity

\begin{tabular}{|c|c|c|c|c|c|c|c|c|}
\hline & 1 & 2 & 3 & 4 & 5 & 6 & 7 & 8 \\
\hline 1. Anonymity and Ownership & 1 & & & & & & & \\
\hline 2. Exploitation & $.412 * *$ & 1 & & & & & & \\
\hline 3. Permission & $.567 * *$ & $.382 * *$ & 1 & & & & & \\
\hline 4. Vulnerable Groups & $.344 * *$ & $.331 * *$ & $.394 * *$ & 1 & & & & \\
\hline 5. Control & $.581 * *$ & $.369 * *$ & $.780 * *$ & $.440^{* *}$ & 1 & & & \\
\hline 6. Unethicality of social media research ${ }^{3}$ & $.757 * *$ & $.673 * *$ & $.811 * *$ & $.700 * *$ & $.822 * *$ & 1 & & \\
\hline 7. Social media researchers' ethical standards ${ }^{4}$ & $-.193 * *$ & $-.230 * *$ & $-.126 * *$ & $-.254 * *$ & $-.156 * *$ & $-.262 * *$ & 1 & \\
\hline 8. The unethicality of SM researchers' actions & $.126^{* *}$ & $.156^{* * *}$ & $.140 * *$ & $.439 * *$ & $.169 * *$ & $.290 * *$ & $-.205^{* *}$ & 1 \\
\hline
\end{tabular}

Table 8: Predictive validity

\begin{tabular}{|c|c|c|c|c|c|c|c|c|}
\hline & 1 & 2 & 3 & 4 & 5 & 6 & 7 & 8 \\
\hline 1. Anonymity and Ownership & 1 & & & & & & & \\
\hline 2. Exploitation & $.412^{* *}$ & 1 & & & & & & \\
\hline 3. Permission & $.567^{* *}$ & $.382^{* *}$ & 1 & & & & & \\
\hline 4. Vulnerable Groups & $.344^{* *}$ & $.331^{* *}$ & $.394^{* *}$ & 1 & & & & \\
\hline 5. Control & $.581^{* *}$ & $.369^{* *}$ & $.780^{* *}$ & $.440^{* *}$ & 1 & & & \\
\hline 6. Information falsification & $.095^{*}$ & $.149^{* *}$ & $.184^{* *}$ & $.095^{*}$ & $.130^{* *}$ & 1 & & \\
\hline 7. Information sharing refusal & $.259^{* *}$ & $.229^{* *}$ & $.198^{* *}$ & $.117^{*}$ & $.164^{* *}$ & $.300^{* *}$ & 1 & \\
\hline 8. Concern for information misuse & $.139^{* *}$ & $.249^{* *}$ & $.228^{* *}$ & $.114^{*}$ & $.184^{* *}$ & $.311^{* *}$ & $.677^{* *}$ & 1 \\
\hline
\end{tabular}

$* *$ Correlation is significant at the 0.01 level (2-tailed); * Correlation is significant at the 0.05 level (2-tailed)

\footnotetext{
${ }^{3}$ Item: Social media research is unethical (7-true)

${ }^{4}$ Item: The ethical standards of social media researchers are very high (7-high)
} 